\title{
TECENDO UMA REDE DE NARRATIVAS: PRÁTICAS CURRICULARES E ARTEFATOS CULTURAIS MOBILIZANDO MEMÓRIAS COLETNAS 1
}

\section{Gabriela Furlan Carcaioli ${ }^{2}$}

\author{
Ana Paula Caetano ${ }^{3}$
}

Sandro Tonso ${ }^{4}$

Juntaram-se para viver uma história e enquanto partilhavam as suas

(re) construíram outra que lhes era antes e continuará depois de todos terem partido

\begin{abstract}
Resumo: O presente texto procura lançar um olhar para a formação de professores do campo no Brasil, apresentando a potencialidade das narrativas como artefatos e práticas curriculares do trabalho docente, a partir de uma experiência de Estágio Supervisionado em um curso de Licenciaturas em Educação do Campo. Nesta experiência, acadêmicos do último ano de formação procuraram, a partir de artefatos, envolver estudantes do Ensino Médio, comunidade escolar e comunidade local em um processo de diálogo de saberes e experiências, produzindo narrativas individuais e coletivas, com objetivo de trabalhar elementos da identidade local dos sujeitos e assim, realizarem a seleção de conteúdos científicos para serem trabalhados durante a regência de aulas. Enfatizando o protagonismo dos movimentos sociais nas lutas por uma educação do/no campo e por uma nova concepção de formação e de escolas nas áreas rurais, o texto destaca o papel das Licenciaturas em Educação do Campo em formar educadores capazes de lutarem por uma sociedade justa e igualitária, posicionando-se criticamente sobre a crise socioambiental e o globalizado modelo hegemônico de desenvolvimento, atuando de forma pedagógica nas comunidades rurais e exercendo a docência interdisciplinar. Narrativas dos estudantes do Ensino Médio em diferentes momentos de parti-
\end{abstract}

\footnotetext{
1 Este trabalho é financiado por fundos nacionais através da FCT - Fundação para a Ciência e Tecnologia, IP., no âmbito da Unidade de Investigação e Desenvolvimento em Educação e Formação - UID/ CED/04107/2019.

2 Mestre em Ensino de Ciências e Matemática; Professora Universidade Federal de Santa Catarina, UFSC, Florianópolis, Brasil. gabriela.carcaioli@ufsc.br

3 Doutora em Ciências da Educação, área Formação de Professores, Professora Associada do Instituto de Educação, Universidade de Lisboa; apcaetano@ie.ulisboa.pt

4 Doutor em Geociências (área de Administração e Política de Recursos Minerais); Professor Pleno da Faculdade de Tecnologia e do Programa de Pós-Graduação em Ensino de Ciências e Educação Matemática da UNICAMP, Campinas, Brasil. E-mail: sandro@unicamp.br
} 
lha de experiências e narrativas produzidas a partir dos relatórios dos acadêmicos estagiários, que analisam e comentam o processo do estágio docência, compõem este texto e dão base para reflexões sobre a potencialidade das narrativas na ressignificação do trabalho docente em sala de aula.

Palavras-chave: Narrativas. Formação de professores. Educação do Campo.

\section{INTRODUÇÃO}

A formação de professores do campo, no Brasil, vai se forjando junto aos movimentos sociais, expressão da resistência e contestação às políticas neoliberais, tendo a luta como expressão política, educativa e artística na busca por uma sociedade mais justa e igualitária. Segundo Arroyo (2012), "os movimentos sociais inauguram e afirmam um capítulo na história da formação pedagógica e docente" (p. 361) ao protagonizarem a luta por uma educação do/no campo, projetando outro modelo de sociedade e escola e fazendo com que outra concepção de formação seja pensada.

Desde sua concepção, os cursos de Licenciatura em Educação do Campo (LEdoC) preveem a formação de educadores capazes de realizarem a gestão de processos educativos escolares, de atuarem de forma pedagógica nas comunidades rurais e de exercerem a docência interdisciplinar. Nas LEdoCs, o objetivo é de formar educadores com noção de totalidade, sendo capazes de formular sínteses básicas e críticas em relação a projetos de agricultura, para desenvolverem seu trabalho educativo a partir de posicionamentos sobre a crise socioambiental e o globalizado modelo hegemônico de desenvolvimento.

Por isso, a experiência apresentada neste texto procura problematizar o uso das narrativas como artefatos para a formação de professores do campo e nas suas potencialidades como práticas curriculares que atendam às necessidades socioambientais e passem a enxergar o sujeito como "sujeito da experiência" (LARROSA, 2002, p. 20). Essa experiência tratada por Larrosa (2002), inspirado em Walter Benjamin é "aquela que nos passa, o que nos acontece, o que nos toca" (idem p. 21); é diferente da informação. Segundo ele, no mundo atual "a informação não deixa lugar para a experiência”, pois a obsessão pela informação não permite que as coisas aconteçam e que o sujeito se deixe tocar pela experiência transmitida. Walter Benjamin em muitos dos seus textos aponta para a pobreza de experiência no mundo atual e teme o fim das narrativas coletivas e experien- 
ciáveis, uma vez que não há mais tempo para contar e ouvir histórias, transmitir experiências e tornar-se narrador, pois para ele, a narrativa é uma forma artesanal de comunicação, que pode estar rareando na vida moderna e capitalista.

O tédio é o pássaro de sonho que choca os ovos da experiência. O menor sussurro nas folhagens o assusta. Seus ninhos - as atividades intimamente associadas ao tédio - já se extinguiram na cidade e estão em vias de extinção no campo. Com isso, desaparece o dom de ouvir, e desaparece a comunidade dos ouvintes. Contar histórias sempre foi a arte de contá-las de novo, e ela se perde quando as histórias não são mais conservadas. Ela se perde porque ninguém mais fia ou tece enquanto ouve a história. Quanto mais o ouvinte se esquece de si mesmo, mais profundamente se grava nele o que é ouvido. Quando o ritmo do trabalho se apodera dele, ele escuta as histórias de tal maneira que adquire espontaneamente o dom de narrá-las. Assim se teceu a rede em que está guardado o dom narrativo. E assim essa rede se desfaz hoje por todos os lados, depois de ter sido tecida, há milênios, em torno das mais antigas formas de trabalho manual. (BENJAMIN, 1983 [1936], p. 9)

As narrativas como prática curricular são apoiadas nos estudos de Ivor Goodson, que desenvolve teorias e práticas em torno de um currículo narrativo em contraposição ao currículo prescritivo, e valoriza as experiências de vida como forma de trabalho nas escolas, engajando estudantes do Ensino Médio (EM), comunidade escolar e comunidade local no processo educativo.

No novo futuro social, devemos esperar que o currículo se comprometa com as missões, paixões e propósitos que as pessoas articulam em suas vidas. Isto seria verdadeiramente um currículo para empoderamento. Passar da aprendizagem prescritiva autoritária e primária para uma aprendizagem narrativa e terciária poderia transformar nossas instituições educacionais e fazê-las cumprir sua antiga promessa de ajudar a mudar o futuro social de seus alunos. (GOODSON, 2007, p. 251)

Além disso, procura-se contribuir para uma visão/postura que articule as diferentes compreensões (individuais e coletivas) da crise socioambiental, com a formação de educadoras/es do Campo, com as possibilidades de enfrentamento - pela educação - desta crise, ao mesmo tempo e articuladamente, mundial e local.

Diante disso, este texto procura refletir sobre a experiência desenvolvida com os acadêmicos do último ano de Licenciatura em Educação do Campo da Universidade Federal de Santa Catarina (Educampo/UFSC) na disciplina de Estágio Supervisionado no Ensino Médio. O estágio docência (ED) foi desenvolvido em uma escola do campo e participaram estudantes do $2^{\circ}$ ano do Ensino 
Médio. Além disso, procurou-se envolver a comunidade escolar e comunidade local no processo. As narrativas foram mobilizadoras das experiências e saberes populares dos alunos, da comunidade escolar e da comunidade local, dando subsídios para a organização do ED nos diferentes momentos pedagógicos e para a seleção de conteúdos na regência das aulas de Ciências da Natureza (CN) (compreendida nas disciplinas escolares de Química, Física e Biologia) e Matemática (MTM). Destaca-se que nos limites deste texto, as reflexões se concentram em um primeiro momento do ED, as "Oficinas Temáticas", atividade principal de produção das narrativas analisadas.

Para que se compreenda o contexto geral dos tempos narrativos aqui apresentados é importante ter em conta que a Educação do Campo, em geral, organiza-se a partir da alternância, ou seja, de momentos pedagógicos que interagem, chamados de "Tempo Universidade" e "Tempo Comunidade". Essa organização procura envolver os acadêmicos em um único processo educativo, articulando a experiência acadêmica (universitária) com a experiência de trabalho e vida na comunidade de origem. Espera-se que os Tempos Universidade (TU) e Tempos Comunidade (TC) estejam imbricados, já que são formas metodológicas de interlocução sobre os mesmos temas.

Os tempos do processo narrativo - lembrar, narrar e refletir sobre o vivido - e da sua análise - pré-análise, leitura temática e leitura interpretativa-compreensiva (SOUZA, 2014) separam-se e interpenetram-se ao longo deste texto, pelo fato dos atores se assumirem em diferentes níveis: da comunidade e dos jovens da escola que são envolvidos na narrativa coletiva da sua própria história, com recurso à oralidade, à escrita e a artefatos culturais; dos acadêmicos estagiários que promovem o trabalho de pesquisa e intervenção usando e analisando as narrativas, desde as investigações etnográficas aos relatórios de final de curso, passando pelas oficinas e pelos projetos desenvolvidos com as comunidades; da formadora-investigadora, que estruturando todo o processo e promovendo o uso das narrativas é uma das autoras ${ }^{5}$ deste capítulo e desenvolve uma análise compreensiva-interpretativa em conjunto com os outros autores, estes situados a um nível mais distanciado pois apenas entram no processo na fase de elaboração deste artigo e desenvolvem um trabalho dialógico de questionamento e aprofundamento interpretativo.Todos esses sujeitos adensam esse texto em seus diferentes níveis estruturais, procurando assim compor uma argumentação pela riqueza das experiências através das narrativas como artefato para o trabalho em sala de aula. 


\section{ENQUADRAMENTO TEÓRICO: NARRATIVAS COMÖ PROCEESSOS DEFORMAÇÃO E INVESTIGAÇÃO}

Assumir as narrativas como processo teórico metodológico que dá base ao trabalho docente na escola, é fazer a opção por uma abordagem dialógica e dialética, que imbrica a construção do sentido por todos os participantes do processo formativo, numa "co-construção de sentido. O sentido não é redutível à consciência dos autores nem à análise dos pesquisadores" (PINEAU, 2006, p.341), o que implica "vivenciar as experiências do eu individual e coletivo para projetar-se a novas possibilidades para ser, fazer, conviver e viver plenamente. É dialogando e refletindo sobre o que somos e fazemos que é possível a projeção [...]"(LOSS, 2017, p. 45).

Além disso, nos interessa a dimensão histórica da narrativa, pois é a partir dela que emerge a narrativa experienciável e que permite aos envolvidos no processo formativo visualizarem aspectos de um tempo e um lugar social (PETRUCCI-ROSA, 2017). Assim, que

No importa ya tanto el mundo interior que es capaz de hacer emerger, sino el mundo de interrelaciones, cogniciones y elementos que intervienen que sea capaz de potenciar en la reconstrucción y comprensión del mismo. (BOLÍVAR \& DOMINGO, 2006, p.23, parágrafo 102)

$\mathrm{O}$ ato de narrar é também o ato de rememorar, de buscar na memória imagens do passado. Para Benjamin, esse é um trabalho árduo, como o de um arqueólogo que no esforço da escavação - encontra, no presente, "o lugar exato em que guardar as coisas do passado” (BENJAMIM, 2013, p.101).

\footnotetext{
Assim, o trabalho da verdadeira recordação deve ser menos o de um relatório, e mais o da indicação exata do lugar onde o investigador se apoderou dessas recordações. Por isso, a verdadeira recordação é rigorosamente épica e rapsódica, deve dar ao mesmo tempo uma imagem daquele que se recorda, do mesmo modo que um bom relatório arqueológico não tem apenas de mencionar os estratos em que foram encontrados os achados, mas, sobretudo os outros, aqueles pelos quais o trabalho teve de passar antes. (BENJAMIN, 2013, p.101)
}

Por isso, a importância da memória coletiva interceptando memória dos an- 
cestrais e seus descendentes:

la mémoire de l'ancêtre est une intersection partielle avec la mémoire de ses descendants, et cette intersection se produit dans un présent commun (...) Mais il faut dire, en sens inverse, que le récit de l'ancêtre introduit déjà la médiation des signes et bascule du cotê de la médiation muette du document et du monument, qui fait de la connaissance du passé historique tout autre chose qu'une mémoire agrandie, exactement comme le monde des contemporains se distinguait de nous par l'anonymat des médiations (RICOEUR, 1985, p. 208-209)

Uma memória coletiva, que é atualizada de forma singular por cada um que a reconta nos espaços coletivos da narração oral, em espaços de formação e de interlocução entre formadores e formandos e nos espaços individuais da escrita e reescrita de relatos e relatórios, é um singular plural, na expressão de Josso (2007), para quem:

A auto-orientação de si, sub-produto de nossa criatividade (a invenção de si), torna-se uma tomada de poder sobre a maneira como cada individualidade pode descobrir sua singularidade, cultivá-la, inscrevendo-se num continuum sociocultural, isto é, numa história coletiva. Essa capacidade criadora, associada às outras dimensões do nosso ser humano, apresenta-se como um objetivo educativo maior (p. 430).

Importa captar a palavra viva na narrativa, na qual a "essência espiritual se comunica na linguagem e não através da linguagem" (BENJAMIN, 1992, p.179), e na qual emerge a sabedoria de um coletivo que na oralidade e na partilha desenvolve o seu sentido de pertença a uma comunidade. Trata-se de uma narrativa que vai sendo transformada à medida que vai sendo contada, numa

[...] sobreposição lenta de camadas finas e transparentes, o que nos dá a imagem mais exata de como a narrativa perfeita vinha à luz do dia, provindo da estratificação de diversas narrativas sucessivas. (BENJAMIN, 1992, p. 38-39).

Pretende-se, assim, aprofundar o potencial formativo das narrativas, aprofundando as suas dimensões reflexiva e mediadora de diálogos entre os diversos participantes e nos níveis de investigação, no aprofundamento da experiência e do conhecimento. 
Em contextos de pesquisa e em práticas de formação, os acordos mútuos entre sujeitos em formação bem como profissionais em acompanhamento e processos de mediação biográfica dialogam sobre o lugar da oralidade e da escrita como dispositivos que possibilitam reflexões sobre a vida, a formação, as trajetórias individuais e coletivas, bem como sobre o respeito à liberdade, autonomia e democracia individual e social (SOUZA, 2014, p. 40)

Deste modo a escrita narrativa faz emergir o seu papel emancipatório,

con un objetivo más político y de revalorización y recuperación de la memoria histórica como denuncia y como baluarte para restablecer la identidad y el valor que llevó a mantener una actitud o una postura de dignidad (...) desde una opción de compromiso político y estrecha vinculación con los movimientos sociales" (BOLÍVAR \& DOMINGO, 2006, p.11, pg. 47).

A linguagem narrativa, as experiências que elas carregam e que assim nos passa, nos acontece e nos toca (LARROSA, 2002), podem apresentar a possibilidade de criação e reinvenção de práticas curriculares na formação de professores, na cultura escolar e nas lutas travadas pelos movimentos sociais, como a crise socioambiental.

\section{ORGANIZAÇÃO METODOLÓGICA DO ESTÁGIO DOCÊNCIA}

Tendo como objetivo formar professores para atuarem nos anos finais do Ensino Fundamental (EF) e no Ensino Médio (EM) nas escolas do campo, o curso de Licenciatura em Educação do Campo prevê em sua grade um total de 432 horas de Estágio Docência (ED), divididos em 4 semestres. A cada semestre, a carga horária de 108 hs de ED supervisionado é dividida na alternância entre TU e TC. No que diz respeito ao ED no Ensino Médio, ele ocorre em dois momentos: durante o $7^{\circ}$ e $8^{\circ}$ semestres de curso. No $7^{\circ}$ semestre, os acadêmicos estagiários experienciam e analisam a realidade no cotidiano escolar e na comunidade local, propondo ações para a relação entre teoria e prática de forma a envolver os diversos sujeitos. No $8^{\circ}$ semestre, o foco se dá na seleção de conteúdos e regência de 20 hs/aula na área de Ciências da Natureza e Matemática (CN e MTM). 
Procurando refletir sobre as narrativas como prática curricular, a maior ênfase se dá ao trabalho desenvolvido durante o $7^{\circ}$ semestre, no qual a partir da análise da realidade, os acadêmicos estagiários desenvolveram uma intervenção chamada "Oficina Temática", de onde emergiram narrativas orais e escritas e subsidiaram a seleção de conteúdos e regência no $8^{\circ}$ semestre.

A partir do quadro 1 apresentado a seguir, organizamos as etapas previstas para o TU e TC, que contribuíram para a construção do ED ao longo do $7^{\circ}$ semestre de curso.

Quadro 1: Planejamento de TU e TC no $7^{\circ}$ e $8^{\circ}$ semestres de estágio docência supervisionado.

\begin{tabular}{|c|c|c|}
\hline Período & TU/TC & Conteúdo/Atividade \\
\hline \multirow[t]{3}{*}{$\begin{array}{l}7^{\circ} \text { Semes- } \\
\text { tre }\end{array}$} & $1^{\circ} \mathrm{TU}$ & $\begin{array}{l}\square \text { Elaboração coletiva do roteiro de observação et- } \\
\text { nográfico; } \\
\square \text { Planejamento da intervenção para melhor conhe- } \\
\text { cer quem são os sujeitos do campo que frequentam o } \\
\text { Ensino Médio na escola. }\end{array}$ \\
\hline & $1^{\circ} \mathrm{TC}$ & $\begin{array}{l}\square \text { Conversa com os professores do Ensino Médio da } \\
\text { escola. } \\
\square \quad \text { Observação de aulas de CN e MTM (Física, Quí- } \\
\text { mica, Biologia e Matemática). } \\
\square \quad 1^{\text {a }} \text { Intervenção em sala de aula - conversa com os } \\
\text { estudantes do Ensino Médio. }\end{array}$ \\
\hline & $2^{\circ} \mathrm{TU}$ & $\begin{array}{l}\square \text { Socialização do primeiro TC; } \\
\square \text { Identificação de situações relevantes a serem de- } \\
\text { senvolvidas; } \\
\square \text { Codificação das situações levantadas pelos acadê- } \\
\text { micos; } \\
\square \text { Planejamento da intervenção com orientadores } \\
\text { (Oficina temática) }\end{array}$ \\
\hline
\end{tabular}




\begin{tabular}{|c|c|c|}
\hline Período & TU/TC & Conteúdo/Atividade \\
\hline & $2^{\circ} \mathrm{TC}$ & $\square$ Intervenção (Implementação da Oficina Temática) \\
\hline & & $\begin{array}{l}\square \text { Definição de um tema específico de estágio com } \\
\text { orientadores e a escola. }\end{array}$ \\
\hline & & $\begin{array}{l}\square \text { Pesquisa teórica do tema específico e organização } \\
\text { de um "dossiề" da temática. }\end{array}$ \\
\hline & $3^{\circ} \mathrm{TU}$ & $\square$ Elaboração do projeto de ensino; \\
\hline & & $\begin{array}{l}\square \text { Seleção de conceitos científicos em acordo com a } \\
\text { escola; }\end{array}$ \\
\hline & & $\square$ Apresentação do projeto de ensino. \\
\hline & $3^{\circ} \mathrm{TC}$ & $\square$ Retorno à comunidade \\
\hline \multirow{6}{*}{$\begin{array}{l}8^{\circ} \text { Semes- } \\
\text { tre }\end{array}$} & $4^{\circ} \mathrm{TU}$ & $\square$ Planejamento do estágio com os orientadores \\
\hline & $4^{\circ} \mathrm{TC}$ & $\square$ Elaboração dos planos de ensino e planos de aula \\
\hline & $5^{\circ} \mathrm{TU}$ & $\square$ Correção dos planos de ensino e aulas \\
\hline & & $\square$ Planejamento final \\
\hline & $5^{\circ} \mathrm{TC}$ & $\begin{array}{l}\square \text { Estágio - regência } 20 \text { hs/aulas e elaboração do re- } \\
\text { latório de estágio }\end{array}$ \\
\hline & $6^{\circ} \mathrm{TU}$ & $\square$ Entrega do Relatório Final de estágio \\
\hline
\end{tabular}

Observa-se que no $1^{\circ} \mathrm{TU}$ a proposta foi compreender o espaço e a comunidade escolar onde seria vivido o ED do EM durante todo o ano $\left(7^{\circ}\right.$ e $8^{\circ}$ semestres), vivendo e experienciando a partir de uma abordagem etnográfica. Baseados em André (1997) e Dayrell (1996), essa abordagem leva em conta questões culturais, éticas, e de valores dos sujeitos que vivem a escola e das comunidades onde elas estão localizadas, ou seja, compreendendo as escolas como espaços socioculturais e o ambiente como um espaço socioambiental. Também nesse período observaram aulas de CN e MTM em todas as turmas de EM para que pudessem conhecer e se envolverem no cotidiano escolar. Com essa dinâmica, realizaram uma breve intervenção na sala de aula em que fariam o ED, com objetivo de suscitar elementos que trouxessem uma temática de interesse aos diversos sujeitos envolvidos no processo.

A partir da observação participante na comunidade, da intervenção e da própria identidade dos acadêmicos estagiários, algumas propostas foram levadas ao $2^{\circ} \mathrm{TU}$ para serem lapidadas a fim de compor um tema principal de ED e estruturar a "Oficina Temática". 
Procurando integrar elementos históricos e culturais da região do Contestado6em Santa Catarina, desde o conflito por terras na região à dimensão da cultura cabocla, ancorada em elementos como a religiosidade, o messianismo, na figura central do Monge São João Maria e nas práticas culturais de uso e cura a partir de plantas e ervas medicinais, a Oficina Temática recebeu o título de "Produção de conhecimento no território do Contestado". Fundamentando-se como prática curricular, os estudantes do EM e os professores foram envolvidos em um processo místico7, tendo as músicas, os objetos e os símbolos representativos da identidade e da cultura do Contestado a atravessar o grande círculo configurado na sala de aula, permitindo que as experiências partilhadas a partir desse encontro fossem capaz de tocar e envolver cada sujeito ali presente, produzindo narrativas orais e escritas, individuais e coletivas.

Finda a oficina, algumas questões foram lançadas com a intenção dos estudantes do EM levarem o tema para ser debatido com suas famílias e assim poderem ouvir histórias, trocar experiências, aprender, e quem sabe seguirem, como dizia Benjamin (1983) tecendo "a rede em que está guardado o dom narrativo" (p. 9).

\section{APRESENTAČ̃̃O DE DADOS E REFLEXÕES - SENSIBILIZAÇÃO, MÍSTICA E PRODUÇÃO DE NARRATIVAS NA OFICINA TEMÁTICA}

Com o objetivo de organizar as reflexões, os resultados serão divididos em quatro momentos em torno da produção das narrativas, sendo o primeiro e segundo momentos concentrados nas narrativas dos estudantes do EM, o terceiro momento centrado no desenvolvimento dos projetos na escola e o quarto em narrativas produzidas a partir dos relatórios dos acadêmicos estagiários.

\footnotetext{
6 A Guerra do Contestado foi um conflito social, ocorrido nos planaltos catarinense e paranaense no Brasil,entre 1912 e 1916, que colocou de um lado grandes fazendeiros e governo e, de outro lado, pequenos agricultores, ervateiros e tropeiros, conhecidos como caboclos. Os caboclos tinham um profetismo popular pelo monge João Maria (São João Maria como é conhecido), e a partir de sua figura criou-se um ambiente cultural de autonomia, um conjunto de práticas sociais e costumeiras do mundo caboclo, autonomia em relação ao Estado, aos proprietários e ao clero católico (MACHADO, 2012).

7 A mística, "[...] é um termo compreendido nas religiões como uma experiência da própria vivência espiritual. [...] pode- se compreender que a mística, em suas manifestações subjetivas, ultrapassa o espectro do sagrado e introduz-se na vida social e na luta política, numa clara aproximação da consciência do fazer presente com a utopia do futuro" (BOGO,2012, p.475). A partir da apropriação do fazer artístico, a mística contribui para mobilizar a cultura e, intencionalmente, construir e trazer à tona a memória coletiva (BOGO, 2012).
} 


\section{$1^{\circ}$ Momento - Produção de narrativas na Oficina Temática}

Procurando sensibilizar os sujeitos ali presentes, organizou-se uma grande roda com elementos místicos que dialogavam com as questões culturais e da identidade cabocla na região do Contestado, como uma bandeira, desenhos, imagens do monge São João Maria e galhos de plantas levadas pelos estagiários. Outros objetos e símbolos levados pelos estudantes do EM e pelos acadêmicos estagiários foram colocados dentro de um velho baú, no centro da roda, junto aos elementos que já compunham a ornamentação. Músicas regionais ecoaram na sala e o baú foi aberto. Um a um, os participantes se levantavam e retiravam o objeto escolhido, retornando aos seus lugares. Os elementos eram objetos que simbolizavam a guerra, a resistência e a identidade cabocla, como um facão de madeira, o monjolo, a cuia do chimarrão,o terço em madeira de imbuia, um pequeno trem, erva - mate, ramos de plantas como o alecrim, hortelã, arruda entre outros elementos, como mostra a Figura 1.

Figura 1: Oficina Temática - Elementos da Guerra do Contestado e da cultura cabocla.

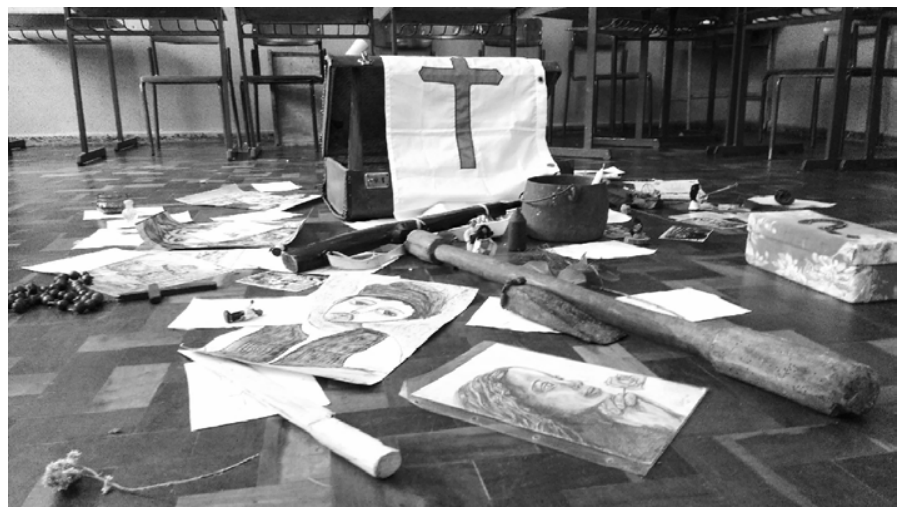

Fonte: Relatórios dos acadêmicos estagiários

Com os objetos em mãos, a proposta era que os participantes, conforme se sentissem mais confortáveis, pudessem expressar oralmente ou de forma escrita, o porquê de suas escolhas. Abaixo estão organizadas algumas narrativas produzidas a partir desse primeiro momento. 


\section{Narrativa 1: Estudante A}

Escolhi o alecrim, porque na minha casa moro eu, minha mãe e meu irmão e acreditamos no poder das ervas. Quando não estamos bem, recebemos algum chá, nós fazemos geralmente chá de alecrim com guiné (não encontrei aqui, mas ali em casa tem), e isso ajuda tanto na espiritualidade, quanto na doença. O alecrim pode ser usado também pra fazer banho de descarrego trazendo muitas energias boas. Ele é usado até mesmo como tempero de carne, que também nos enche de boas energias pelo poder que tem. E ali em casa nós usamos bastante esses tipos de erva, tem arruda, alecrim, guiné, hortelã. Tem bastante ervinhas assim que é usado pra banho, chá, e ali em casa foi sempre assim, pois nós acreditamos muito no poder das ervas.

\section{Narrativa 2: Estudante B}

Eu escolhi a erva-mate, que tem bastante lá onde eu moro, $e$ sempre o pai, a vó tomam chimarrão que é feito dela. Antes era feito no pilão, a vó cortava, socava no pilão e esquentava, fazia a erva caseira mesmo. O mês que ela fazia a erva, que é o mês mais adequado é agosto, que ela brota melhor, nos outros meses já pega o inverno, e aí já não brota bem.

\section{Narrativa 3: Estudante C}

Terço pequeno - porque simboliza um pouco da fé dos meus familiares. No tempo da guerra tinha muita dor e sofrimento, e as pessoas tinha que buscar a fé. Esse terço me lembra também a minha bisavó, ela tinha muito em casa, tinha muita fé, e quando ela faleceu eu vi um familiar meu colocar na mão dela um parecido com esse aqui, e isso me lembra muito ela e da fé forte que ela tinha. Ela tinha muita fé, no terço, em nossa senhora, no São João Maria. Me lembra ela.

\section{$2^{\circ}$ Momento: Produção de narrativas a partir do material escrito}

As narrativas 3 e 4 apresentadas abaixo foram produzidas a partir dos materiais escritos que os estudantes do EM retornaram à escola após realizaram a atividade requerida no contexto familiar. As Figuras 2 e 3 são parte do material dos estudantes $\mathrm{D}$ e E, respectivamente.

\section{Narrativa 4: Material escrito - Estudante D}

[...] É uma prática da minha família fazer um mutirão para ir cortar erva - mate, fazer as bolas de erva, depois nós secamos a erva e 
mandamos para o monjolo onde outro grupo vai moendo [...]

\section{Narrativa 5: Material escrito - Estudante E}

[...] João Maria dizia que "quem não soubesse ler a natureza é analfabeto de Deus". [...] ele conhecia um conjunto de ervas nativas e seus efeitos terapêuticos. [...] Algumas são cozidas outras podem ser misturadas na comida [...]

Figura 2: Imagem do material escrito do estudante D

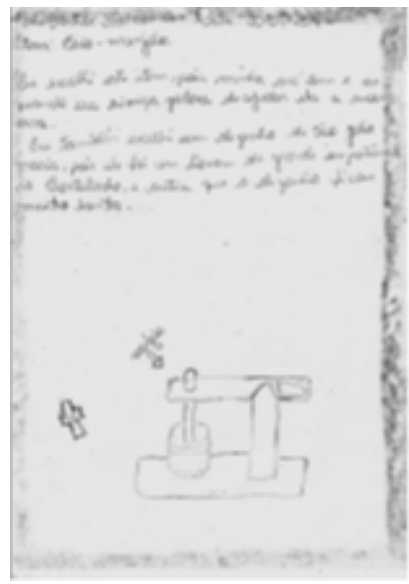

Figura 3: Imagem do material escrito do estudante $\mathrm{E}$

Fonte: Relatório dos acadêmicos estagiários

Lançando um olhar para as narrativas de 1 a 6 identifica-se diversas dimensões da identidade e da cultura cabocla, como o uso e manipulação de ervas e plantas medicinais para o tratamento de enfermidades e alimentação, as técnicas de cultivo e beneficiamento da erva-mate, a fé e os saberes em torno do monge São João Maria, a coletividade da comunidade em torno dos mutirões, etc. As experiências vivenciadas no âmbito da comunidade, da família, são mobilizadoras de memórias e saberes, que adentram agora o âmbito escolar a fim de mobilizarem conhecimentos científicos. 
Destaca-se também nas Figuras 2 e 3, respectivamente, a expressão dos estudantes a partir de desenhos como o monjolo, utilizado na moagem da erva-mate e a bandeira do Contestado, símbolo da resistência cabocla durante a guerra. Além disso, as narrativas impulsionam memórias individuais e coletivas, sentimentos e saberes populares que deram origem a outras narrativas, registradas nos relatórios finais dos estagiários a partir da análise crítica deles sobre o processo.

Narrativa 6: Acadêmicos estagiários 1 e 2 - relatório coletivo

Esse primeiro registro, foi compartilhado em roda novamente, devolvendo o item ao centro [...]. Foi o momento mais fantástico da aula, porque além de propiciar o diálogo durante a elaboração do registro, o movimento de escrita, dúvidas dos/as estudantes, e lançar uma série de questões sobre o Território do Contestado (sobre máquinas como o trem, sobre benzedeiras, etc.), muitos das/os estudantes sentiram-se confortáveis para contar um pouco de si, de sua identidade, e coisas particulares de suas famílias, que não contariam se não estivessem naquela atividade. As estudantes que geralmente parecem caladas e estão na borda, interagiram porque estabeleceram esse laço de confiança ao sentirem-se valorizadas, $o$ que na nossa perspectiva, é crucial. Esta atividade tratava da identidade assim como tratou a $1^{a}$ intervenção, com o diferencial de chegar às práticas e conhecimentos locais, entretanto, foi muito melhor sucedida. A roda, o momento místico, os objetos de família que remetiam ao Contestado mantiveram o tom de curiosidade, de leveza à aula e proporcionaram um sentimento de correspondência e identificação muito forte dos/as estudantes. A tarefa foi a de elaborar um memorial com algumas questões orientadoras, dando maior corpo às narrativas pela possibilidade de conversar com familiares.

\section{$3^{\circ}$ Momento: $O$ desenvolvimento dos projetos na escola}

Experiências comuns suscitadas a partir das narrativas produzidas na oficina contribuíram para estreitar laços de confiança, pertencimento e de identidade dos sujeitos, dentro daquela sala de aula, como comentam os acadêmicos estagiários na narrativa 5, que culminou na organização do trabalho de ED no $8^{\circ}$ semestre.

Procurando continuar com o tom narrativo durante a regência das 20h/aula no $8^{\circ}$ semestre, a presença da avó de uma estudante para contar sua experiência como benzedeira e seus trabalhos com ervas medicinais envolveu a comunidade e contribuiu para romper algumas barreiras entre os conhecimentos científicos 
que estavam presentes na regência das aulas e dar espaço aos saberes populares, que transitam na comunidade e raramente adentram o espaço escolar. Além da avó, também se envolveram em uma roda de músicas, professores da escola, que são compositores de canções regionais ligadas às histórias do período da guerra.

Com esses diversos sujeitos e saberes que puderam adentrar a sala de aula, os conhecimentos científicos também precisavam estar presentes e em diversos momentos, dialogar com a seleção de conteúdos do currículo escolar, o que se tornou uma das maiores dificuldades encontradas pelos acadêmicos estagiários. Não parecia haver tanta dificuldade em unir os conhecimentos populares que adentraram a sala e os conhecimentos científicos, mas sim em seguir a seleção de conteúdos previstas para aquele momento no currículo escolar. Os acadêmicos estagiários foram envolvidos nesse processo, sendo participantes ativos na tomada de decisões:

Narrativa 7: Acadêmicos estagiários 1 e 2 - relatório coletivo

Buscamos as narrativas entendendo-as como expressão do saber popular e este como ciência, pelas discussões nas disciplinas de Laboratório e Saberes e Fazeres.

Além disso, o diálogo com a direção da escola e os professores desde o início do ED sempre foi muito importante e permitiu que eles participassem das tomadas de decisões, adquirissem confiança no trabalho desenvolvido e amparassem as dificuldades que surgiram ao longo do ano.

\section{$4^{\circ}$ momento: Narrativas produzidas a partir dos relatórios dos acadê- micos estagiários}

Este processo foi objeto de reflexão nas próprias narrativas, pelos acadêmicos estagiários nos seus relatórios onde, para além de analisarem o processo do ED e do uso de narrativas com os estudantes e a comunidade, alertam para questões éticas que lhes foram surgindo ao aprofundarem memórias individuais e coletivas ligadas à guerra:

\section{Narrativa 8: Acadêmicos estagiários 1 e 2 - relatório coletivo}

Nossa oficina deixou-nos satisfeito, e nossa preocupação ao analisá-la é como lidar de uma forma não superficial com o que foi uma guerra na região do Contestado, e o que isso significa na formação de um povo [...]. 
Narrativa 9: Acadêmico estagiário 1 - relatório individual

Esquecer a guerra já foi uma política de governo. Muitas pessoas não gostam de falar sobre isso ainda. Há cemitérios esquecidos nos matos, ossos de famílias caçadas e massacradas. A região já foi chamada de faixa da miséria, pelos baixos índices de IDH. E o que foi compartilhado por alguns estudantes do EM são experiências com alto teor sentimental $e$ devem ser abordadas com cuidado. Mesmo tendo que trabalhar a área de CN e MTM e objetivando chegar aos conteúdos dessas áreas com o relato das práticas familiares, depois de ter esse tipo de exposição, como podemos ser indiferentes? Nossa postura deve ser o de trabalhar a identidade positivada destes sujeitos, contribuindo para uma educação crítica e de qualidade para a classe trabalhadora. Mas, qual preparo temos para saber trabalhar o psíquico que estamos revolvendo, e o bem-estar desses sujeitos ao trazerem à tona memórias familiares que estão ligadas a violência contra o povo?

\section{Narrativa 10: Acadêmicos estagiários 1 e 2 - relatório coletivo}

[...] por parte das e dos estudantes, o sentimento de correspondência com o tema da oficina, compartilhando algumas narrativas familiares; $e$ durante a atividade de produção e registro escrito, foi notável a predominância de marcas da fala coloquial, e limites de escrita e leitura.

O conteúdo dos relatórios dão conta da capacidade crítica que os acadêmicos foram desenvolvendo com o trabalho realizado e da atenção e empatia que foram aprofundando no contato com aqueles com quem se relacionaram. Acentuam, ainda, o papel mediador das narrativas e dos artefatos no desenvolvimento das relações entre estudantes e estagiários, entre estudantes e suas famílias, entre os supervisores e os acadêmicos estagiários. Mas também questionam a responsabilidade da universidade e dos estagiários, que ao estreitaram as relações com a escola e com a comunidade podem estar a criar expectativas às quais não dão depois continuidade. Além disso, podem estar a abrir feridas que depois não têm condições para trabalharem mais profundamente.

Destaca-se que essa formação foi construída a partir da ideia de totalidade, conceito fundante na Educação do Campo, a partir do diálogo de saberes, da articulação entre teoria e prática, da estreita relação entre local e global, procurando dialogar com as diferentes dimensões de ambiente (ecológica, cultural,política, social), ou seja, o socioambiental. Também, para favorecer este diálogo, a produção e partilha de narrativas surgem como processos de mediação cognitiva 
e social. A análise de narrativas e de todo o trabalho etnográfico prévio, em articulação com a análise dos currículos escolares permitiu estabelecer as pontes pelas quais se definiram os conteúdos e processos pedagógicos desenvolvidos no último semestre de estágio.

\section{CONSIDERAÇÕES FINAIS}

Queremos, neste final de texto, acentuar a importância da construção de uma biografia coletiva com recurso às narrativas orais, desencadeadas por artefatos com significado cultural e pessoal, transportadas por cada um para o debate onde se juntam, centro simbólico, quase místico, onde se cruzam histórias, imaginários, mitos, fortalecendo o sentido de comunidade e de pertença.

Uma história intensa, experiência nova, vivida por dentro, pelos que, de dentro e de fora, se encontram e da qual emergem aprendizagens para a vida e, o que é o mesmo, para a relação com o mundo e consigo próprios. Não serão os mesmos, estes estagiários, estacionados temporariamente num território que lhes é alheio, mas onde se reconhecem numa humanidade partilhada. Onde percebem o poder das raízes e tradições. Onde se angustiam com as implicações de um trabalho que mexe com o trauma coletivo. Onde pressentem o seu lugar, como mediadores que se deixam inseminar pelos saberes da universidade e das comunidades, transportando-os dentro de si e fazendo-os germinar no contato com ambas. Produzindo assim um currículo vivo nas escolas onde os estudantes e professores aprendem uns com os outros ressignificando os seus saberes. Aí deixando um rastro e partindo depois, para viver outras histórias. 


\section{REFERÊNCIAS}

ANDRÉ, Marli E. D. A de. Tendências atuais da pesquisa na escola. Cad. CEDES, Campinas, v.18, n.43, Dez.1997.

ARROYO, Miguel. Formação de Educadores do Campo. Verbete do Dicionário da Educação do Campo. EPSJV/Expressão Popular, 2012. p. 361-367.

BENJAMIN, Walter. Imagens do pensamento/Sobre o haxixe e outras drogas: Escavar e recordar. 1ed. Belo Horizonte: Autêntica, 2013 [1926]

Sobre a arte, técnica, linguagem e política. Lisboa: Relógio d’Água,

1992.

Narrador. In: Os Pensadores. $2^{\circ}$ ed. São Paulo: Abril Cultural, 1983 [1936]. 57-74 p.

BOGO, Ademar. Mística. Verbete do Dicionário da Educação do Campo. EPSJV/ Expressão Popular, 2012, 475 - 479 p.

BOLÍVAR, Antonio \& DOMINGO, Jesús. La investigación biográfica y narrativa en .Iberoamérica: Campos de desarrollo y estado actual, Forum: Qualitative Social Research, vol 7, nº

DAYRELL, Juarez. A escola como espaço sócio-cultural. In: DAYRELL, J. (org.). Múltiplos olhares sobre educação e cultura. Belo Horizonte: Editora da UFMG, 1996.

GOODSON, Ivor F. Currículo, Narrativa e Futuro Social. Revista Brasileira de Educação, v.12, n.35, p.241-252, mai/ago.2007.

JOSSO, Marie-Christine. A transformação de si a partir da narração de histórias de vida. Educação. Porto Alegre/RS, n³ (63), p. 413-438, set/dez, 2007.

LARROSA, Jorge. Notas sobre a experiência e o saber de experiência. Revista Brasileira de Educação. Jan/Fev/Mar/Abr, No 192002 . p.20-28.

LOSS, Adriana Salete. Formação de professores/educadores: Autoformação pessoal, social e profissional. Curitiba: CRV, 2017.

MACHADO, P. P. Guerra do Contestado. Os reflexos cem anos depois. Entrevista especial com Paulo Pinheiro Machado: entrevista. [15 de outubro, 2012]. São Leopoldo: Instituto Humanitas Unisinos. Entrevista concedida a Instituto Humanitas Unisinos. Disponível em: http://www.ihu.unisinos.br/entrevistas/514385-guerra-do-contestado-os-reflexos-cem-anos-depois-entrevista-especial-com-paulo-pinheiro-machado Acesso em: 06 de jan. 2019. 
PETRUCCI-ROSA, Maria Inês. Práticas Curriculares na formação profissional: uma compreensão singular para as narrativas como forma de transgressão. Linhas Críticas, Brasília, DF, v.23, n.52, p. 560-577, jun. 2017 a set. 2017.

PINEAU, Gaston. As histórias de vida como artes formadoras de existência. In: SOUZA, Eliseu Clementino de; ABRAHÃO, Maria Helena Menna Barreto (Org.). Tempos, narrativas e ficções: a invenção de si. Porto Alegre: EDIPUCRS, 2006.

RICOEUR, Paul. Temps et récit. 3. Le temp raconté. Paris: Éditions du Seuil, 1985.

SOUZA, Elizeu Clementino. Diálogos cruzados sobre pesquisa (auto)biográfica: análise compreensiva-interpretativa e política de sentido. Educação, Santa Maria, vol 39, nº11, pp. 39-50, 2014. 


\title{
WEAVING A NETWORK OF NARRATIVES: CURRICULAR PRACTICES AND CULTURAL ARTIFACTS MOBILIZING COLLECTIVE MEMORIES
}

\begin{abstract}
This paper seeks to take a look at the training of rural teachers in Brazil, presenting the potential of narratives as artifacts and curricular practices of teaching work, from a Supervised Internship experience in a Rural Education Degree course. In this experience, academics from the last year of formation sought, from artifacts, to involve high school students, the school community and the local community in a process of dialogue of knowledge and experiences, producing individual and collective narratives, aiming to work on elements of identity. place of the subjects and thus, to select the scientific contents to be worked during the conducting of classes. Emphasizing the leading role of social movements in the struggle for rural education and for a new conception of training and schools in rural areas, the text highlights the role of Rural Education Degrees in training educators capable of fighting for a just society. and egalitarian, critically positioning itself on the socio-environmental crisis and the globalized hegemonic model of development, acting in a pedagogical way in rural communities and exercising interdisciplinary teaching. Narratives of high school students in different moments of sharing experiences and narratives produced from the reports of trainee academics, who analyze and comment on the teaching internship process, compose this text and provide the basis for reflections on the potentiality of narratives in the resignification of students. teaching work in the classroom.
\end{abstract}

Keywords: Narratives. Teacher training. Rural Education. 


\title{
TEJIENDO UNA RED DE NARRATNAS: PRÁCTICAS CURRICULARES Y ARTEFACTOS CULTURALES QUE MOVILIZAN MEMORIAS COLECTIVAS
}

\begin{abstract}
Resumen: Este documento busca echar un vistazo a la capacitación de maestros rurales en Brasil, presentando el potencial de las narrativas como artefactos y prácticas curriculares del trabajo docente, a partir de una experiencia de pasantía supervisada en un curso de grado de educación rural. En esta experiencia, los académicos del último año de formación buscaron, a partir de artefactos, involucrar a estudiantes de secundaria, la comunidad escolar y la comunidad local en un proceso de diálogo de conocimiento y experiencias, produciendo narrativas individuales y colectivas, con el objetivo de trabajar en elementos de identidad. lugar de las asignaturas y así, seleccionar los contenidos científicos a trabajar durante la realización de las clases. Al enfatizar el papel principal de los movimientos sociales en la lucha por la educación rural y por una nueva concepción de la formación y las escuelas en las zonas rurales, el texto destaca el papel de los Grados de Educación Rural en la formación de educadores capaces de luchar por una sociedad justa. e igualitario, posicionándose de manera crítica en la crisis socioambiental y el modelo de desarrollo hegemónico globalizado, actuando de manera pedagógica en las comunidades rurales y ejerciendo la enseñanza interdisciplinaria. Narrativas de estudiantes de secundaria en diferentes momentos de intercambio de experiencias y narrativas producidas a partir de informes de académicos en formación, que analizan y comentan sobre el proceso de pasantía docente, componen este texto y proporcionan la base para reflexionar sobre la potencialidad de las narrativas en la resignificación de los estudiantes. Trabajo docente en el aula.
\end{abstract}

Palabras clave: Narrativas. Formación docente. Educación rural. 